\title{
Glyoxylate Reductase/Hydroxypyruvate Reductase: A Novel Prognostic Marker for Hepatocellular Carcinoma Patients after Curative Resection
}

\author{
Yinglian Pan ${ }^{a}$ Runzhou $\mathrm{Ni}^{\mathrm{a}}$ Qingchun Deng ${ }^{c}$ Xiaodong Huang ${ }^{\mathrm{b}}$ \\ Yixin Zhang ${ }^{b}$ Cuihua Lu ${ }^{a}$ Feifei Li ${ }^{b}$ Da Huang ${ }^{c}$ Song He ${ }^{b}$ Buyou Chen ${ }^{a}$ \\ a Department of Oncology, Affiliated Hospital of Nantong University, and ${ }^{\mathrm{b}}$ Department of Pathology, Affiliated \\ Cancer Hospital of Nantong University, Jiangsu, and ' Department of Clinical Laboratory, Tongji Medical College, \\ Huazhong University of Science and Technology, Wuhan, China
}

\section{Key Words}

Hepatocellular carcinoma · Tumor marker · Primary

hyperoxaluria type 2

\begin{abstract}
Objective: Glyoxylate reductase/hydroxypyruvate reductase (GRHPR) is a key enzyme in the glyoxylate cycle. Its deficiency causes primary hyperoxaluria type 2 . We first noticed that GRHPR was also lost in human hepatocellular carcinoma (HCC) and proliferative HCC cells. The aim of the present study was to investigate the potential clinical utility of GRHPR in HCC. Methods: The expression of GRHPR in tissues and cells was detected by Western blotting. Immunohistochemistry was utilized to examine the expression patterns of GRHPR and Ki-67 in a surgical cohort of HCC and adjacent liver tissues. Results: We demonstrated that GRHPR showed a lower expression in tumor tissues than in nontumoral tissues. GRHPR was negatively correlated with Ki-67 $\left(R^{2}=0.771, p<0.05\right)$ and GRHPR was reduced in proliferative Huh7 cells $(p<0.05)$. Patients with negative GRHPR both in tumor tissues and nontumoral tissues had a significantly shorter survival time than those with positive GRHPR ( $p<$ 0.001). Multivariate analysis established that GRHPR was detected in nontumoral tissues as an independent prognostic factor for patients with HCC. Conclusions: Our findings sug-
\end{abstract}

gest that the GRHPR defect in noncancerous tissues may represent an independent predictor of poor survival for HCC patients after curative resection and that there may be a link between GRHPR and prognosis of HCC patients.

Copyright $\odot 2013$ S. Karger AG, Basel

\section{Introduction}

Human hepatocellular carcinoma (HCC) is one of the most common malignant tumors worldwide, especially in Africa and Asia [1]. Driven by the high prevalence of hepatitis B virus infection in Chinese populations, hepatitis $B$ virus-related liver cirrhosis and/or HCC has become one of the main disease burdens in China [2]. Unfortunately, the long-term prognosis of patients with HCC remains unsatisfactory in spite of recent advances in surgical techniques and medical management [3]. This poor outcome is, in part, attributable to the fact that HCC is clinically and genetically a heterogeneous disease $[4,5]$. There is no single 'size' that fits all. Therefore, there is an urgent need to discover and identify new biomarkers on

Yinglian Pan, Runzhou Ni and Qingchun Deng contributed equally to this work.

\section{KARGER}

E-Mail karger@karger.com

www.karger.com/pat
(C) 2013 S. Karger AG, Basel

$1015-2008 / 13 / 0803-0155 \$ 38.00 / 0$
Buyou Chen

Department of Oncology, Affiliated Hospital of Nantong University 20 Xisi Road

Nantong 226001, Jiangsu Province (PR China)

E-Mail hsntt111@foxmail.com 
Table 1. Correlation of GRHPR protein expression and clinicopathological features of $120 \mathrm{HCC}$ patients

\begin{tabular}{|c|c|c|c|c|c|c|c|c|}
\hline \multicolumn{2}{|c|}{ Clinicopathological features } & \multirow[t]{2}{*}{$\mathrm{n}$} & \multicolumn{3}{|c|}{ Intratumoral GRHPR expression } & \multicolumn{3}{|c|}{ Peritumoral expression } \\
\hline & & & negative & positive & $\mathrm{p}$ & negative & positive & $\mathrm{p}$ \\
\hline \multirow[t]{2}{*}{ Sex } & Male & 96 & 66 & 30 & 0.512 & 23 & 73 & 0.074 \\
\hline & Female & 24 & 16 & 8 & & 2 & 22 & \\
\hline \multirow{2}{*}{ Age } & $\leq 49.2$ years & 59 & 45 & 14 & 0.05 & 10 & 49 & 0.211 \\
\hline & $>49.2$ years & 61 & 37 & 24 & & 15 & 46 & \\
\hline \multirow[t]{3}{*}{ Differentiation } & Well & 12 & 3 & 9 & 0.003 & 3 & 9 & 0.596 \\
\hline & Moderate & 64 & 46 & 18 & & 15 & 49 & \\
\hline & Poor & 44 & 33 & 11 & & 7 & 37 & \\
\hline \multirow[t]{2}{*}{ Metastasis } & Yes & 19 & 17 & 2 & 0.024 & 5 & 14 & 0.170 \\
\hline & No & 101 & 65 & 36 & & 17 & 84 & \\
\hline \multirow{2}{*}{ Vascular invasion } & Yes & 35 & 27 & 8 & 0.132 & 11 & 24 & 0.059 \\
\hline & No & 85 & 55 & 30 & & 14 & 71 & \\
\hline \multirow[t]{2}{*}{ Encapsulation } & Absent & 42 & 31 & 11 & 0.217 & 12 & 30 & 0.105 \\
\hline & Present & 77 & 50 & 27 & & 13 & 64 & \\
\hline \multirow[t]{2}{*}{ Tumor size } & $\leq 5 \mathrm{~cm}$ & 60 & 35 & 25 & 0.015 & 4 & 56 & 0.01 \\
\hline & $>5 \mathrm{~cm}$ & 60 & 47 & 13 & & 21 & 39 & \\
\hline \multirow[t]{2}{*}{ a-Fetoprotein } & $\leq 50 \mathrm{ng} / \mathrm{ml}$ & 52 & 28 & 24 & 0.003 & 8 & 44 & 0.145 \\
\hline & $>50 \mathrm{ng} / \mathrm{ml}$ & 68 & 54 & 14 & & 17 & 51 & \\
\hline \multirow[t]{2}{*}{ Tumor multiplicity } & Single & 77 & 51 & 26 & 0.326 & 16 & 61 & 0.580 \\
\hline & Multiple & 43 & 31 & 12 & & 9 & 34 & \\
\hline \multirow{2}{*}{$\begin{array}{l}\text { Hepatitis B surface } \\
\text { antigen }\end{array}$} & Yes & 87 & 68 & 19 & 0.01 & 18 & 69 & 0.566 \\
\hline & No & 33 & 14 & 19 & & 7 & 26 & \\
\hline \multirow[t]{2}{*}{ Liver cirrhosis } & Yes & 98 & 67 & 31 & 0.586 & 12 & 76 & 0.273 \\
\hline & No & 22 & 15 & 7 & & 3 & 19 & \\
\hline
\end{tabular}

the basis of which we can stratify HCC patients in a better way [6].

In the liver, the glyoxylate cycle contributes to two metabolic functions, i.e. urea and glucose synthesis. One of the key enzymes in this pathway is glyoxylate reductase/hydroxypyruvate reductase (GRHPR) whose dysfunction in humans causes primary hyperoxaluria type 2 $(\mathrm{PH} 2)$, a disease resulting in oxalate accumulation and formation of kidney stones [7]. In our study, we noticed that GRHPR was also lost in some HCC cases. This finding greatly aroused our interest and made us wonder if the GRHPR defect is a common occurrence in HCC, and if the evaluation of GRHPR expression can enable us to better stratify HCC patients and provide individualized health care. To solve these questions, we examined the expression patterns of GRHPR in a surgical cohort of HCC patients who underwent curative resection by immunohistochemistry (IHC). We now report for the first time that HCC is a heterogeneous disease in terms of GRHPR status, and by evaluating the GRHPR status in both tumor and noncancerous adjacent tissues, we can sort out a subset of HCC patients with poor survival.

\section{Materials and Methods}

\section{Cell Line and Cell Culture}

The normal hepatic cell line Lo2 and four HCC cell lines, HepG2, Huh7, Hep3B and SMMC-7721, were maintained in Dulbecco's modified Eagle's medium supplemented with $10 \%$ fetal bovine serum and $1 \%$ penicillin-streptomycin at $37^{\circ} \mathrm{C}$ with $5 \% \mathrm{CO}_{2}$. For cell cycle analysis, cells were trypsinized, fixed in $70 \%$ ethanol for $1 \mathrm{~h}$ at $4^{\circ} \mathrm{C}$ and then incubated with $1 \mathrm{mg} / \mathrm{ml} \mathrm{RNase} A$ for $30 \mathrm{~min}$ at $37^{\circ} \mathrm{C}$. Subsequently, cells were stained with propidium iodide (50 $\mu \mathrm{g} / \mathrm{l}$; Becton Dickinson, San Jose, Calif., USA) in PBS, $0.5 \%$ Tween-20, and analyzed using a Becton Dickinson flow cytometer BD FACScan and Cell Quest acquisition and analysis programs.

\section{Patients and Tissue Specimens}

Formalin-fixed, paraffin-embedded, primary HCCs from 120 patients who underwent curative resection from 2003 to 2006 were randomly selected from the archives of the Department of Pathology, Affiliated Cancer Hospital of Nantong University. Diagnosis of all cases of HCC was confirmed histologically by an experienced pathologist, based mainly on examination of sections stained with $\mathrm{H} \& \mathrm{E}$. Tumor differentiation was graded by the Edmondson grading system. This cohort of patients with HCC included 96 (80\%) men and $24(20 \%)$ women, with a mean age of 49.2 years, and their clinical and pathological characteristics are summarized in table 1 . The average follow-up time was 41.1 months (median 41.5, range 1.0-91.0). 
In this study, all diagnoses were formulated by expert pathologists, according to the criteria for terminology established by the International Working Party. Tumor differentiation was based on the criteria of the World Health Organization Classification of Tumor (2000). In addition, for GRHPR Western blotting analysis, fresh tissue specimens from 8 patients with HCC who underwent surgical resection were collected in 2012. Snap-frozen tumorous and adjacent nontumorous tissue specimens were stored at $-80^{\circ} \mathrm{C}$. None of the patients received preoperative anticancer treatment. The study was approved by the surveillance and ethics committee of the institution, and informed consent was obtained from all patients.

\section{Western Blot Analysis}

Total protein was extracted using RIPA buffer (Beyotime, Haimen, PR China). Equal amounts of protein were separated by $10 \%$ SDS-PAGE and blotted to polyvinylidene fluoride membranes (Millipore, Billerica, Mass., USA). Membranes were blocked with $5 \%$ skimmed milk at room temperature for $2 \mathrm{~h}$ and incubated overnight with primary antibodies: anti-GRHPR antibody (1:500 dilution; Cell Signaling, Beverly, Mass., USA) or anti- $\beta$-actin antibody (1:1,000 dilution; Santa Cruz, Calif., USA). After three 5-min washes, membranes were incubated with horseradish peroxidase-conjugated secondary antibody (1:5,000 dilution; Santa Cruz) and visualized with enhanced chemiluminescence (ECL Kit, Pierce, Rockford, Ill., USA). Protein bands were scanned and quantified using Quantity One software (Bio-Rad, Hercules, Calif., USA).

\section{Tissue Microarray and IHC}

Tissue microarrays (TMAs) were constructed in accordance with a previously described method [8]. Duplicates of 0.6-mmdiameter cylinders (one cylinder taken from intratumoral tissue and one cylinder from peritumoral tissue) were punched from representative areas of an individual donor tissue block and re-embedded into a recipient paraffin block at a defined position, using a tissue arraying instrument (Beecher Instruments, Silver Spring, Md., USA).

The TMA blocks were cut into $5-\mu \mathrm{m}$ sections and processed for IHC according to a previously described protocol. Briefly, TMA slides were dried for $6 \mathrm{~h}$ at $65^{\circ} \mathrm{C}$, dewaxed in xylene, rehydrated through graded alcohol and quenched in $3 \%$ hydrogen peroxide. Antigen retrieval was performed by microwave heating at high power $(750 \mathrm{~W})$ in $10 \mathrm{mM}$ sodium citrate buffer for three cycles of $5 \mathrm{~min}$ each. After blocking with normal serum for $1 \mathrm{~h}$ at room temperature, the slides were incubated for $2 \mathrm{~h}$ at $37^{\circ} \mathrm{C}$ with anti-human GRHPR rabbit polyclonal antibody (diluted 1:200; Santa Cruz Biotechnology) and Ki-67 monoclonal antibody (diluted 1:100, clone 7B11; Zymed Laboratories, San Francisco, Calif., USA). After rinsing five times with $0.01 \mathrm{~mol} / \mathrm{l} \mathrm{PBS}$, the detection of the primary antibody was achieved with a secondary antibody (Envision; Dako, Glostrup, Denmark) for $1 \mathrm{~h}$ at room temperature and stained with 3,3-diaminobenzidine after washing in PBS again. Finally, the sections were counterstained with Mayer's hematoxylin, dehydrated and mounted.

\section{Evaluation of Immunohistochemical Staining}

The staining intensity of TMAs was blindly evaluated by two experienced pathologists under a light microscope. The staining intensity score from 0 to 3 (I0, I1-I3) and the proportion of tumor cells for that intensity to the total number of tumor cells was recorded as $5 \%$ increments from a range of $0-100$ (P0, P1-P3). Final

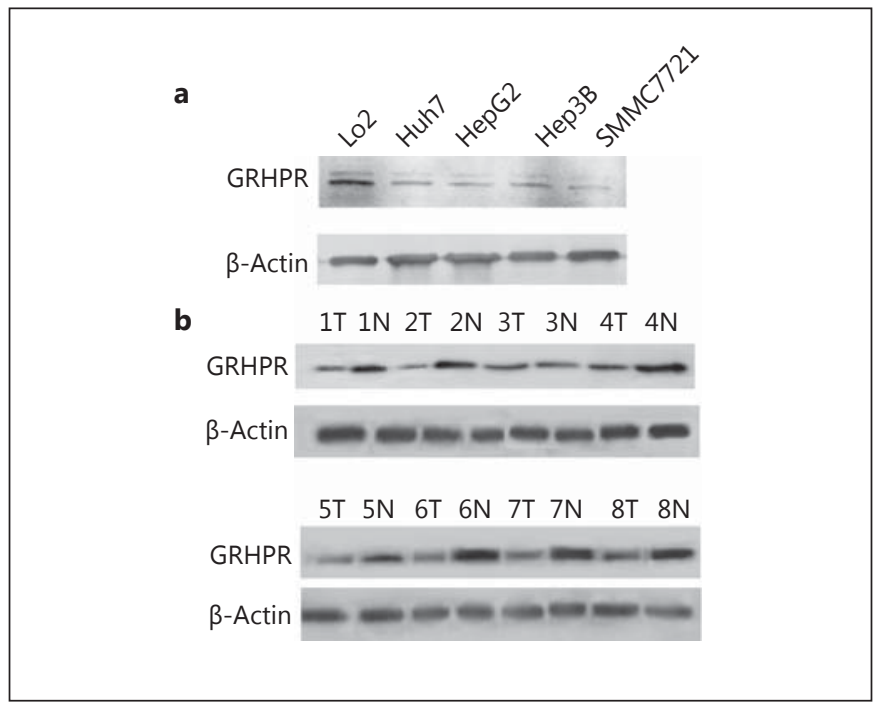

Fig. 1. Expression of GRHPR in HCC cells and tissues as determined by Western blotting. a The four HCC cell lines, Huh7, HepG2, Hep3B and SMMC7721, exhibited lower levels of GRHPR expression than the normal liver cell line Lo2. b Downregulated GRHPR expression was detected in 7/8 cases of primary HCC tissues compared to adjacent noncancerous liver tissue. T = HCC tissue; $\mathrm{N}=$ noncancerous liver tissue.

intensity scores were determined using the following formula: total score $=\mathrm{I} 1 \times \mathrm{P} 1+\mathrm{I} 2 \times \mathrm{P} 2+\mathrm{I} 3 \times \mathrm{P} 3$. In case of disagreement (score discrepancy $>0.5$ ), the slides were re-examined and a consensus was reached by the observers.

\section{Statistical Analysis}

Statistical analyses were carried out using the SPSS 11.0 statistical program (Chicago, Ill., USA). Receiver operating characteristic (ROC) curve analysis was performed to determine the cutoff point for GRHPR positivity. Plots of overall survival according to marker expression were drawn using the Kaplan-Meier method, and statistical significance between survival curves was compared using the log-rank test. Multiple Cox proportional hazards regression was carried out to identify the independent factors which had a significant impact on patient survival. A difference was considered significant if the $\mathrm{p}$ value from a two-tailed test was $<0.05$.

\section{Results}

\section{GRHPR Expression Is Decreased or Lost in HCC}

Western blotting analysis revealed that the GRHPR expression was significantly lower in all four HCC cell lines than in normal liver cell line Lo2, which was used for comparison (fig. 1a). In liver tissues, downregulated GRHPR expression was observed in $87.5 \%$ (7/8) primary HCC tissues (fig. 1b). 


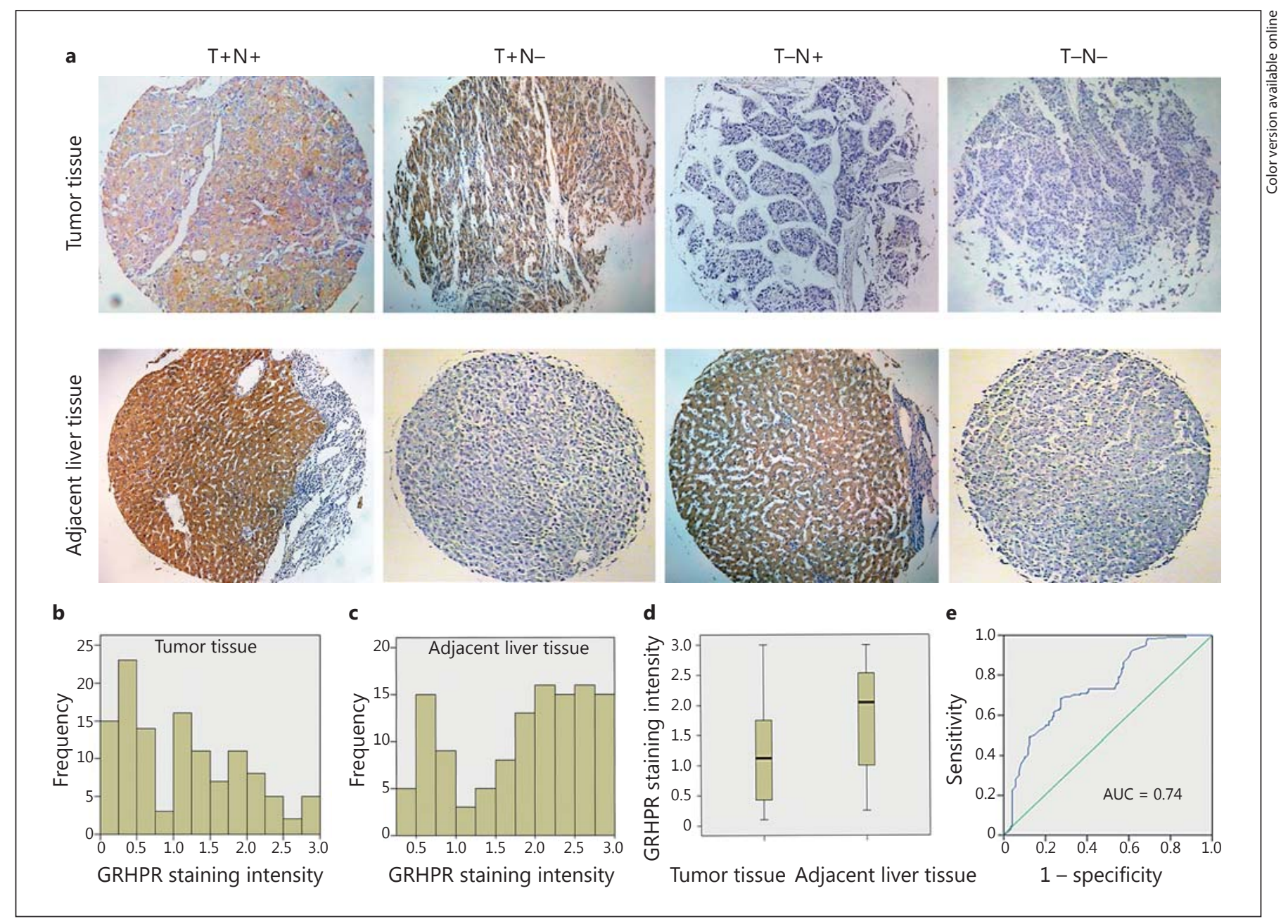

Fig. 2. Expression dynamics of GRHPR in HCC and noncancerous liver tissues as examined by IHC. a Representative patterns of GRHPR expression in HCC (upper panels) and noncancerous liver tissues (lower panels), as examined in 4 HCC patients. $\mathrm{T}+\mathrm{N}+=$ Positive GRHPR expression in both HCC and noncancerous liver tissues; $\mathrm{T}+\mathrm{N}-=$ GRHPR was positive in HCC tissue and negative in noncancerous liver tissue; T-N+ = GRHPR was negatively expressed in HCC but positively expressed in noncancerous liver tis- sue; $\mathrm{T}-\mathrm{N}-=$ both HCC and noncancerous liver tissues without GRHPR expression. b, c GRHPR expression in HCC (b) and noncancerous liver tissues (c) varied greatly from patient to patient, as indicated by the histograms. $\mathbf{d}$ The box plot shows the mean staining intensity of GRHPR in HCC and noncancerous liver tissues of 120 patients. e To identify a single, optimal cutoff point for GRHPR overexpression, a ROC curve was plotted. AUC = Area under the curve.
Evaluation of GRHPR Expression Dynamics in Tumor and Noncancerous Adjacent Tissue by IHC

The degree of immunoreactivity of GRHPR, which was observed primarily in the cytoplasm, and semi-quantification of GRHPR expression in our cohort $(n=120)$ demonstrated that GRHPR expression was downregulated in the majority of tumor tissues, and the median GRHPR staining intensity of tumor and noncancerous tissues was 1.12 and 2.04, respectively (fig. 2d). On the other hand, GRHPR expression varied greatly in tumor and noncancerous adjacent tissue from patient to patient (fig. 2b, c).

\section{Selection of Cutoff Point for GRHPR Overexpression and Patient Stratification Based on GRHPR Status}

As mentioned above, GRHPR expression showed great variation in HCC. To identify a single, optimal cutoff point for GRHPR overexpression, ROC curve analysis was carried out (fig. 2e). The point on the curve that had both maximum sensitivity and specificity was selected as the cutoff 
point. Thus, GRHPR with a staining intensity above the value of 1.53 was designated as overexpressed. To make things simple, we used $\mathrm{T}$ to stand for tumor tissue and $\mathrm{N}$ to stand for noncancerous adjacent tissue. HCC patients with a follow-up date available $(\mathrm{n}=100)$ were classified into four subgroups: the $\mathrm{T}-\mathrm{N}+$ pattern was observed in 48 patients, the $\mathrm{T}+\mathrm{N}+$ pattern in 27 patients, the $\mathrm{T}+\mathrm{N}-$ pattern in 8 patients and the $\mathrm{T}-\mathrm{N}$ - pattern in 17 patients (fig. 2a).

\section{Correlation between GRHPR Expression and}

Clinicopathological Characteristics of HCC Patients

In HCC tissues, correlation analysis revealed that positive expression of GRHPR was conversely correlated with differentiation, metastasis, tumor size, $\alpha$-fetoprotein and hepatitis B surface antigen $(\mathrm{p}<0.05$; table 1$)$ but was not related to sex, age, vascular invasion, encapsulation, tumor multiplicity and liver cirrhosis. In noncancerous tissues, further analysis showed us that positive expression of GRHPR was not significantly related to differentiation, metastasis, $\alpha$-fetoprotein and hepatitis B surface antigen, but to tumor size $(\mathrm{p}<0.001$; table 1$)$.

\section{Positive Expression of GRHPR in HCC Negatively Correlated with Tumor Proliferation}

We then investigated whether GRHPR expressions correlated with the Ki-67 immunoreactivity, which has been reported to be a useful proliferation marker [6]. Representative examples of reactivity for GRHPR and Ki67 are shown in figure 3a. In the GRHPR negative expression tissues, Ki-67 showed conversely higher nucleus positive expression. The outcome presented a negative correlation between GRHPR and Ki-67 ( $p<0.011$; fig. 3d). Based on this, we detected the expression of GRHPR in HCC cells. Huh7 cells were arrested in G1 by serum deprivation after $72 \mathrm{~h}$, and upon adding serum, the cells entered into the $S$ phase; we then detected that the expression of GRHPR was markedly reduced after serum release 24 h later ( $\mathrm{p}<0.003$; fig. 3b, $\mathrm{c}, \mathrm{e})$.

\section{Association between GRHPR Status and Survival and}

\section{Hazard Risks of HCC Patients}

Kaplan-Meier analysis showed that the mean 5-year disease-free survival time for $\mathrm{T}+\mathrm{N}+$ patients was 59.8 months [SE 5.7; 95\% confidence interval (CI) 48.6-70.9] and 49.4 months (SE 4.0; 95\% CI 41.4-57.4) for T-N+ patients, versus 27.3 months (SE 9.0; 95\% CI 9.6-44) for $\mathrm{T}+\mathrm{N}$ - patients and 10.1 months (SE 3.2; 95\% CI 5.9-14.3; $\mathrm{p}<0.001$; fig. 4a) for $\mathrm{T}-\mathrm{N}$ - patients. In the 5 -year overall survival analysis, the mean survival time for $\mathrm{T}+\mathrm{N}+, \mathrm{T}-\mathrm{N}+, \mathrm{T}+\mathrm{N}-$ and $\mathrm{T}-\mathrm{N}-$ patients was 66.8 (SE 6.2; 95\% CI 54.6-79.0), 56.4 (SE 4.9;
95\% CI 47.0-66.0), 25.0 (SE 7.8; 95\% CI 9.6-40.3) and 10.0 months (SE 2.1; 95\% CI 5.9-14.3), respectively ( $<<0.01$; fig. $4 \mathrm{~b}$ ), while the mean survival time for all patients was 49.5 months (SE 3.6; 95\% CI 42.3-56.6). Pairwise comparisons showed that the difference in the mean survival time between $\mathrm{T}+\mathrm{N}+$ and $\mathrm{T}-\mathrm{N}+$ patients might result from random error $(p=0.202)$, while the differences in the mean survival time between other groups were statistically significant. Multivariate Cox regression analysis revealed that the GRHPR status, when added to the model, could supplant tumor size and tumor stage as a death hazard, and the death hazard for a $\mathrm{T}-\mathrm{N}$ - patient was 17.3 times that of a $\mathrm{T}+\mathrm{N}+$ patient (table 2), indicating that the GRHPR status is an independent hazard risk for HCC patients.

\section{Discussion}

GRHPR has long been a Cinderella among liver enzymes. Clinicians did not know much about it except that its dysfunction can lead to PH2. Our initial Western blotting showed that HCC cell lines and tissues had much lower GRHPR expression levels than adjacent liver tissues and a normal hepatic cell line. These observations suggested that the loss of GRHPR expression in HCCs could not be an isolated phenomenon and challenged our attention. We also found that the expression of GRHPR negatively correlated with proliferation in HCC cells.

Hepatocarcinogenesis is a complex process requiring multiple factors [9]. We are not sure if GRHPR is an active participant or a mere bystander in this process. However, our Cox multivariate analysis gave us some clue as to the possible underlying mechanisms. That is, when we introduced the GRHPR status into the model, well-established prognostic predictors such as tumor size and stage were removed from the model. It is likely that the variation in survival time that is explained by tumor size and stage can also be explained by GRHPR status. In fact, this kind of predictor supplantation is not unprecedented. For example, enhancer of zeste homologue 2, which enhances HCC cell growth and tumorigenicity [10], has supplanted tumor size as an independent prognostic predictor in a previous study [11]. Taken together, it is likely that GRHPR deficiency, if it is an active participant in hepatocarcinogenesis, may have the potential to promote cell growth and metastasis in HCCs.

It has been proposed that metabolic disease and malignancy share common biological mechanisms [12-15]. In recent years, the rising metabolic disorders such as nonalcoholic steatohepatitis and type 2 diabetes mellitus are 
Fig. 3. Expression of GRHPR in proliferative HCC cells. Negative GRHPR expression and positive Ki-67 in a common case (left panels) and the reverse outcome (right panels). Scatterplot of GRHPR versus Ki67 with the regression line showing a correlation using Spearman's correlation coefficient ( $p<0.05$; lower right panel). b Flow cytometry quantitation of cell cycle progress in Huh7 cells. Cells after serum starvation for $72 \mathrm{~h}$ (S $72 \mathrm{~h}$ ); then, medium containing $10 \%$ FBS was added for the indicated times (R 4 h, R 8 h, R 12 h, R 24 h). c Huh7 cells were serum deprived for $72 \mathrm{~h}$ and, upon serum release, cell lysates were prepared and analyzed by Western blot using antibodies directed against GRHPR; $\beta$-actin was used as a control for protein load and integrity. $\mathrm{S}=$ Serum starvation; $\mathrm{R}=$ serum release
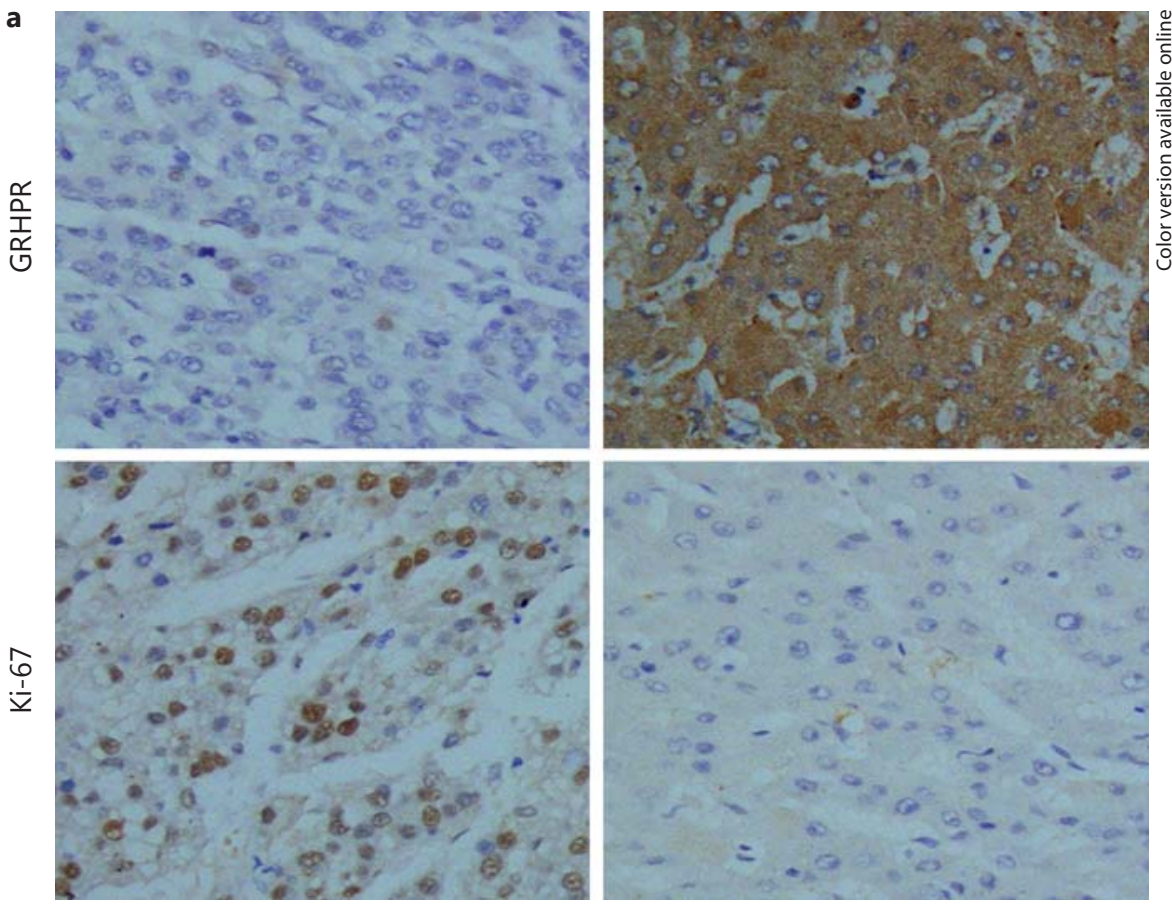

b

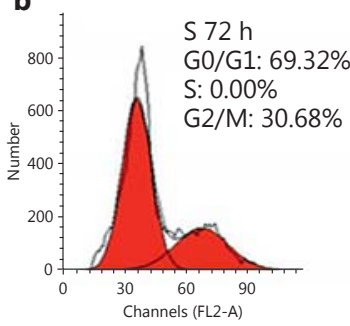

$\mathrm{R} 12 \mathrm{~h}$

G0/G1: $57.72 \%$

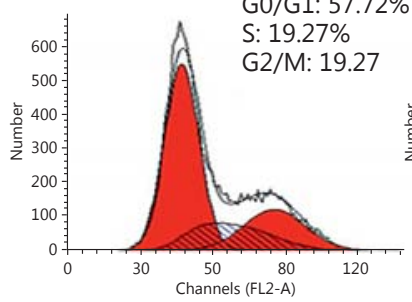

d

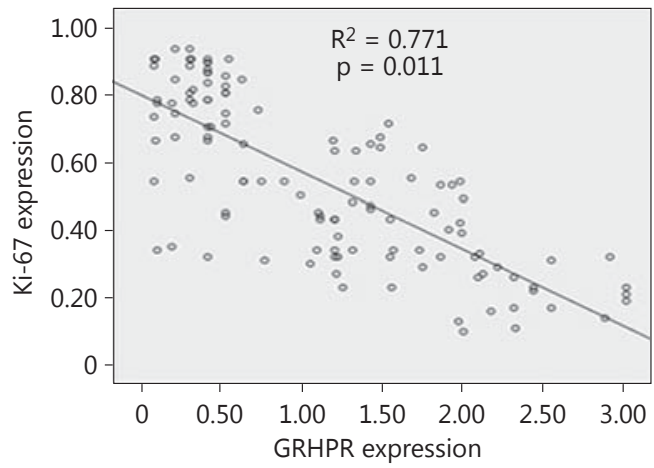

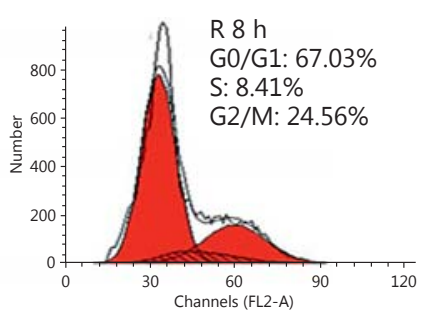

$\mathrm{R} 24 \mathrm{~h}$

G0/G1: $56.20 \%$

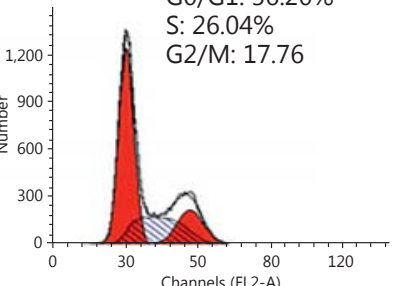

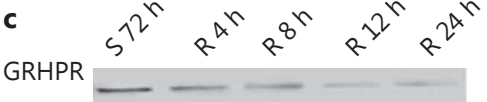

$\beta$-Actin e

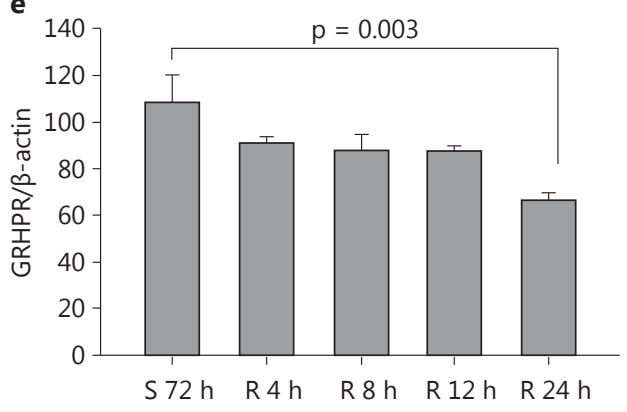




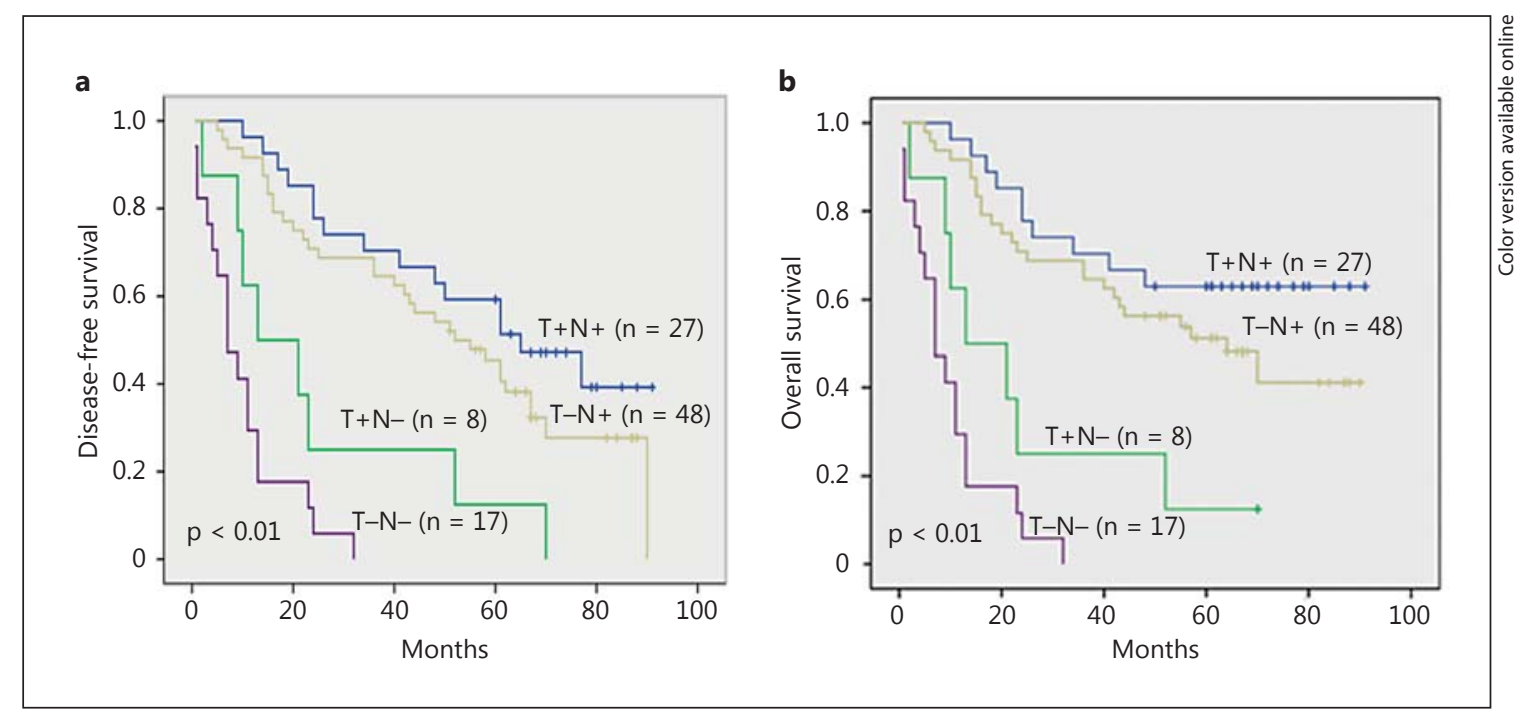

Fig. 4. Disease-free (a) and overall survival (b) of HCC patients with different GRHPR expression patterns. Patients with GRHPR deficiency in noncancerous liver tissues had much poorer outcomes than those with overexpressed GRHPR after curative resection.

considered to be causes of hepatocarcinogenesis. Our data revealed that HCC patients with a positive GRHPR in adjacent tissues showed much better survival than those without, irrespective of whether they had positive GRHPR in tumor tissues or not. This means that the GRHPR status in 'healthy' adjacent tissues is more important than that in unhealthy tumor tissues in determining the prognosis of a given patient. These observations are impressive because GRHPR deficiency in the liver is the touchstone for PH2 [16]. It is likely that HCC patients with worse prognosis actually correspond to those with $\mathrm{PH} 2$. Thus, the possibility that $\mathrm{PH} 2$ may have a role in hepatocarcinogenesis cannot be formally ruled out. It is necessary to point out that our current study is of retrospective nature. Further prospective studies with a larger population are needed to validate the conclusions of this study and to establish the link between $\mathrm{PH} 2$ and HCCs.

To sum up, in this study, we describe the protein expression patterns of GRHPR in a cohort of human HCCs and adjacent liver tissues and demonstrate the potential utility of GRHPR as a prognostic marker in HCCs. We show, for the first time, that GRHPR deficiency in the liver and a lower expression in proliferative HCC cells proved to be an independent predictor for patient survival. Moreover, our results hint at a possible link between $\mathrm{PH} 2$ and HCCs, and this may improve our understanding of hepatocarcinogenesis and provide a new potential strategy for HCC treatment.
Table 2. Multivariate analysis showing the overall survival rate for HCC patients

\begin{tabular}{lll}
\hline Variables & Hazard ratio & p value \\
\hline $\begin{array}{l}\text { Equation without GRHPR status } \\
\text { Tumor size ( } \leq 5 \text { vs. }>5 \mathrm{~cm})\end{array}$ & $0.572(0.327-1.004)$ & 0.051 \\
$\quad \begin{array}{l}\text { Tumor multiplicity } \\
\quad \text { (single vs. multiple) }\end{array}$ & $0.512(0.297-0.884)$ & 0.16 \\
$\quad \begin{array}{l}\text { Metastasis (no vs. yes) } \\
\text { Equation with GRHPR status } \\
\text { Tumor multiplicity } \\
\quad \text { (single vs. multiple) }\end{array}$ & $0.527(0.277-1.004)$ & 0.051 \\
GRHPR status & $0.341(0.198-0.587)$ & $0.000^{*}$ \\
T+N+ & Reference category & \\
T+N- & $5.418(2.028-14.478)$ & $0.001^{*}$ \\
T-N+ & $1.662(0.79-3.490)$ & 0.180 \\
T-N- & $17.334(7.226-41.584)$ & $0.000^{*}$ \\
\hline
\end{tabular}

Figures in parentheses are $95 \%$ CIs. ${ }^{*} \mathrm{p}<0.01$.

\section{Acknowledgements}

We thank Professor Shen (Department of Immunology and Microbiology, Nantong University, Jiansu, PR China) for his technical assistance. This study was financially supported by the National Natural Science Foundation of China (No. 31070723). 


\section{References}

1 Parkin DM: Global cancer statistics in the year 2000. Lancet Oncol 2001;2:533-543.

$\checkmark 2$ Poon D, Anderson BO, Chen LT, Tanaka K, Lau WY, Van Cutsem E, Singh H, Chow WC, Ooi LL, Chow P, Khin MW, Koo WH: Management of hepatocellular carcinoma in Asia: consensus statement from the Asian Oncology Summit 2009. Lancet Oncol 2009;10: 1111-1118.

$>3$ Bruix J, Sherman M: Management of hepatocellular carcinoma. Hepatology 2005;42: 1208-1236.

4 Fransvea E, Paradiso A, Antonaci S, Giannelli G: HCC heterogeneity: molecular pathogenesis and clinical implications. Cell Oncol 2009;31:227-233.

$\checkmark 5$ Boyault S, Rickman DS, de Reynies A, Balabaud C, Rebouissou S, Jeannot E, Herault A, Saric J, Belghiti J, Franco D, Bioulac-Sage P, Laurent-Puig P, Zucman-Rossi J: Transcriptome classification of HCC is related to gene alterations and to new therapeutic targets. Hepatology 2007;45:42-52.

6 Mann CD, Neal CP, Garcea G, Manson MM, Dennison AR, Berry DP: Prognostic molecular markers in hepatocellular carcinoma: a systematic review. Eur J Cancer 2007;43:979992.
7 Genolet R, Kersten S, Braissant O, Mandard S, Tan NS, Bucher P, Desvergne B, Michalik L, Wahli W: Promoter rearrangements cause species-specific hepatic regulation of the glyoxylate reductase/hydroxypyruvate reductase gene by the peroxisome proliferator-activated receptor alpha. J Biol Chem 2005;280:2414324152.

$>8$ Cai MY, Luo RZ, Chen JW, Pei XQ, Lu JB, Hou JH, Yun JP: Overexpression of ZEB2 in peritumoral liver tissue correlates with favorable survival after curative resection of hepatocellular carcinoma. PLoS One 2012;7: e32838.

$\checkmark 9$ Bergsland EK: Molecular mechanisms underlying the development of hepatocellular carcinoma. Semin Oncol 2001;28:521-531.

10 Chen Y, Lin MC, Yao H, Wang H, Zhang AQ, Yu J, Hui CK, Lau GK, He ML, Sung J, Kung HF: Lentivirus-mediated RNA interference targeting enhancer of zeste homolog 2 inhibits hepatocellular carcinoma growth through down-regulation of stathmin. Hepatology 2007;46:200-208.

11 Cai MY, Tong ZT, Zheng F, Liao YJ, Wang Y, Rao HL, Chen YC, Wu QL, Liu YH, Guan XY, Lin MC, Zeng YX, Kung HF, Xie D: EZH2 protein: a promising immunomarker for the detection of hepatocellular carcinomas in liver needle biopsies. Gut 2011;60:967-976.
12 Zhu H, Shyh-Chang N, Segre AV, Shinoda G, Shah SP, Einhorn WS, Takeuchi A, Engreitz JM, Hagan JP, Kharas MG, Urbach A, Thornton JE, Triboulet R, Gregory RI, Altshuler D, Daley GQ: The Lin28/let-7 axis regulates glucose metabolism. Cell 2011;147:81-94.

13 Vander Heiden MG: Targeting cancer metabolism: a therapeutic window opens. Nat Rev Drug Discov 2011;10:671-684.

14 Hao HX, Khalimonchuk O, Schraders M, Dephoure N, Bayley JP, Kunst H, Devilee P, Cremers CW, Schiffman JD, Bentz BG, Gygi SP, Winge DR, Kremer H, Rutter J: SDH5, a gene required for flavination of succinate dehydrogenase, is mutated in paraganglioma. Science 2009;325:1139-1142.

15 Yun J, Rago C, Cheong I, Pagliarini R, Angenendt P, Rajagopalan H, Schmidt K, Willson JK, Markowitz S, Zhou S, Diaz LA Jr, Velculescu VE, Lengauer C, Kinzler KW, Vogelstein B, Papadopoulos N: Glucose deprivation contributes to the development of KRAS pathway mutations in tumor cells. Science 2009;325:1555-1559.

16 Giafi CF, Rumsby G: Kinetic analysis and tissue distribution of human D-glycerate dehydrogenase/glyoxylate reductase and its relevance to the diagnosis of primary hyperoxaluria type 2. Ann Clin Biochem 1998;35: 104-109. 